\title{
Le Penseur meets LEntrepreneur: Pushing the Envelope of Ethnography in Business Writing Research ${ }^{1}$
}

\author{
Deborah Begoray \\ University of Winnipeg
}

\begin{abstract}
Although ethnography holds much promise for the furtherance of epistemological pursuits in business writing research, its traditional practices and procedures can prove to be limiting for the investigator. This paper examines the impetus underlying three shifts in focus to adapt ethnography for the study of proposal writing undertaken by a group of technical writers: from interpretation to establishing relationships, from fieldnotes to videorecords, and from narration to a model. Traditional approaches were not abandoned but rather augmented by these other practices.
\end{abstract}

IN THE INVESTIGATION OF LITERACY IN THE WORKPLACE, or indeed anywhere else, one often encounters the problems of recording and representing the complex processes of reading and writing, listening and speaking. Ethnography has become a popular way of studying detail, nuance and depth in these communication events; however, the method can frequently become problematic. Although I was initially attracted to ethnography for its literary qualities and its traditional roots in the study of cultures, as a researcher investigating collaborative business writing I soon became aware of some of its limitations.

Ethnography, in common with all qualitative research, takes as its credo that

the nature of the social world must be discovered; that this can only be achieved by first-hand observation and participation in "natural" settings

1. An earlier version of this paper was presented at the annual meeting of the American Educational Research Association, San Francisco, California, April, 1995. This research was supported by a Doctoral Fellowship from the Social Sciences and Humanities Research Council of Canada. The author would like to acknowledge the helpful comments of two anonymous reviewers. 
guided by an exploratory orientation; that research reports must capture the social processes observed and the social meanings that generate them (Hammersley, 1992, p. 12).

Ethnography, then, would seem perfectly suited to studying complex social phenomena such as the joint composition of a business proposal in a high technology company (see also Ede and Lunsford, 1990).

Over a period of two years, 1991-1993, I was involved in just this type of research activity at an international computer systems integrator (called hereafter "Cerebellum, Inc."). In particular, I studied the collaborative development of a proposal as a recorder and occasional participant (during this part of my research $I$ had no official instructional function at Cerebellum, but writers often included me in their discussions by asking casual questions). There were eight writers involved (including senior managers and directors, sales personnel and technicians) in the construction of the proposal document over an eleven day period. These events occurred toward the end of my two years at Cerebellum.

Ethnography in this context offered me a way to examine composition behaviours in a context of social relationships and conventions which I hoped might explain "a phenomenon in terms of a culture" (Brown and Herndl, 1986, p. 12). Moreover, I valued an ethnographic approach as an opportunity to become more aware of and, perhaps, more able to confront power-relationship issues between researcher and researched. It is difficult for us not to perpetuate a hegemonic separation between cultures, whether the "other" culture is students or business. Any analysis of events must, I believe, address issues in power and power-sharing. As Doheny-Farina (1993) reminds us: "[b]ecause there is work to be done in the world, we need to walk that tightrope between ethical self-consciousness and our attempts to observe and analyze systematically and perceptively what is going on around us" (p. 267).

In this particular research situation, I found it necessary to push ethnography's traditional processes on three fronts. First, I changed the focus of my investigation from interpretation to establishing relationships. Second, I moved from reliance on fieldnotes to using more videorecords. Finally, I added to ethnographic narrative with a model of the social writing process. This paper discusses these expansions of ethnography's traditional boundaries. 


\section{Ethnography at "Cerebellum, Inc."}

\section{From Interpretation to Establishing Relationships}

In a discussion of an early shift in the evolution of ethnographic practice, Geertz (1973) points out the difficulties faced by the ethnographer who is trying not merely to observe but rather to interpret a culture of "others." He calls upon the work of Oxford philosopher Gilbert Ryle who considers "the general question of what Le Penseur is doing" (p.6). What, indeed, does the thinker do? He thinks, of course - but is the answer so simple? Can we claim to understand Le Penseur merely from observation and analysis? What else might he be doing? And what, after all, is the act of thinking for him? We cannot pretend merely to analyze such acts (as though we could discover some ultimate truth) but must rather acknowledge that we are interpreting them. Ryle (and Geertz) consider the difficulty of differentiating between the wink and the twitch. How can we know the intention of the person engaged in one seemingly simple act? Discovering the answer (or even an answer) is fraught with challenge for the ethnographer engaged in an act of interpretation. Interpretation, however, there must be if one is to engage honestly in ethnography. And in comparison with Le Penseur, how much more complex, I wondered, are the communication behaviours of, for example, the business writer (l'entrepreneur) and, therefore, how much more resistant to interpretation? What else might be done?

Howe and Eisenhart (1983) maintain that "justifying qualitative research largely consists of developing and articulating methodological design and analysis standards" (p. 2). Clearly, although the researcher can learn much from studying the classical rules of ethnography, "a methodology must be judged by how well it informs research purposes, at least as much as by how well it matches a set of conventions" (pp. 4-5). The conventions, of observation and interpretation for example, continue to be challenged as the ethnographic research community problematizes its practices and reinvents itself in response to new insights. In much the same fashion as Geertz found it necessary to shift focus from observation to interpretation in the pursuit of ethnography, $\mathrm{I}$, too, saw conditions which called for a shift in focus from interpretation to a greater emphasis on establishing relationships.

Although I began my investigation of literacy behaviours in the business 
world as an interpretive ethnographer, attempting primarily to "generate insights, explain events, and to seek understanding" (Anderson, 1989, p. 253) of another culture, such understanding did not entirely meet my evolving research purposes. As a writing educator, I wanted to build relationships with members of Cerebellum's culture leading to information sharing which might lead to more effective writing intervention. I wanted not merely to realize that mine was but one possible rendition; I sought also to stand more firmly within the community and build connections with its members. I spent much of my time with Cerebellum allowing myself to participate as fully as possible as a member of the corporate family, offering advice when asked, discussing collaboration issues and yet still remaining constant to my role as researcher. Once again, ethnography seemed the perfect way to begin my investigation. Best (1981) observes that the researcher/subject relationship is an intimate one "based upon trust and confidence" (p. 113). The ethnographer, he maintains, somewhat blithely perhaps, "gets inside the minds of the subjects, while at the same time interpreting the behaviour from his or her own perspective."

In my quest to establish a relationship with my informants, I found it necessary to push the boundaries of generally accepted practices in the gathering and representing of ethnographic data. The university and the corporation often find themselves at odds with each other. Etter-Lewis (1991) reminds us, however, that " $[\mathrm{w}] \mathrm{e}$ must cease to view the world around us in terms of duality and/or opposing pairs" (p. 56) but should rather look for the possibilities for relationships. I was able to visit Cerebellum twice weekly, and gradually established relationships with many employees. I soon discovered that I was learning about their ways of doing writing by connecting informally with each of them. We built on a common interest: we were all writers and more or less interested in how writing worked (and why it sometimes did not work).

I did not begin by trying to effect a detente between two dissimilar cultures, the university and the corporation, but merely tried to interpret a selected behaviour of some members of this "other" culture. I had signed confidentiality agreements as a condition of gaining research access at Cerebellum, but my concerns became deeper than allowing a vital document into the hands of a business competitor. I wanted to deal fairly with people that I knew and liked. More often than not, senior directors rose to my defence when I asked to sit in on meetings and objections were raised on confidentiality issues. Because of the trust, cooperation and consideration 
accorded to me, I owed them at least as much consideration as I decided how and what to gather. I struggled with the difficulties of dealing with data to meet the needs of my academic audience and my informant audience. Remaining a detached interpreter of events was not satisfactory - neither was "selling out" to the corporate agenda (perhaps by becoming a proofreader of their proposal document). Clearly, some other stance had to be found.

The literature presents several approaches to the problem of audience identification. In a more traditional vein, Agar (1980) suggests a "funnel approach" to ethnography (p. 203) in which the investigator turns her attention to her academic audience as the primary one. She shifts her dealings with her informants moving from humanity to science, from involvement to detachment, from breadth to depth, from subordination to dominance, and from friend to stranger. Hammersley, in similar fashion (1992, p. 76) advises that in the final analysis, the most important audience for the ethnography must be other researchers.

Other scholars, however, express doubt about such behaviour towards informants. Wolf (1992) comments: "To my thinking, if there is any crisis in ethnography, it is a growing uncertainty about our dual responsibility to our audiences and our informants" (p.137). She further reminds us that the lines are blurring between these two groups. Indeed, troubling charges of exclusion may arise from an imbalance of attention to academic audiences which seems to denigrate the importance of informants. Lather (1991, p. 50), for example, would oblige university investigators to adopt a role in the emancipation of informants. However, as a researcher I felt strongly a need for balance. I owed a debt to the research community to gather data of interest in order to provide new insights in writing research. Further, however, I was involved with informants also interested in becoming an audience for these insights.

The first way in which I challenged traditional ethnographic practice, then, was to institute a shift in focus from interpretation to relationship building without turning my back on my duties to other researchers.

\section{From Fieldnotes to Videorecords}

The second change in emphasis I made was to rely more heavily on videorecords and less on fieldnotes. Cerebellum's proposal writers wrote in a number of genres and as they did, they consulted with each other in a number of ways: over the phone, in the hallway, over coffee, in meetings and in e-mail messages. I gathered and examined artifacts but was soon 
dissatisfied, convinced that the key to understanding (much less relating to) these writers was not to be found in these products of writing alone. A traditional ethnographic approach seemed to be the answer, and so I began to sit in offices and take fieldnotes (in traditional unobtrusive style) on the various writing processes of Cerebellum's culture.

My job was made easier when one informant talked aloud as she wrote in my presence in the manner of a spontaneous think-aloud protocol. But what about other writers? For me, the problem of gathering data intensified as other Cerebellum writers, as quiet as Le Penseur, broke their intense periods of drafting to seek advice from others. The conversations were rapid and fascinating. I could not capture all of the words, the linguistic features, nor the paralinguistic elements such as tone or stress in my notes but even less could I capture the nonverbal behaviour of body language and facial movements. Important too were contextual elements (desk decorations, the presence or absence of windows and doors, the proximity of other workers) all of which began to seem important to the writing process. Also I realized that while I had a sense of the meaning of most of the conversations, I was hampered by my lack of background in the technical language of computer professionals. I had the sense that what I could record with my pen was but an incomplete or even misleading facade of the whole reality which was proposal writing at Cerebellum, Inc.

My solution was to move from relying on fieldnotes to an almost exclusive use of videorecording to gather data. Using videotaping procedures in an ethnographic fashion offered me great opportunities for the kind of detailed study needed to examine the talk that is collaboration. Using videotaping is certainly not new to ethnographic practice. Jacob (1987) points out that ethnographers of communication often use videotaping because it "preserves data in close to their original form...continuous...comprehensive ... [so that the] naturally occurring sequence and duration of actions is recorded" (p. 20). Commonly, however, videotaping is merely supplementary to writing fieldnotes or gathering artifacts. The advantage of focusing on videotaping, in this research situation then, is that collaborative business writing by its very nature involves rapid, technical talk (and nonverbal behaviour) which can be captured on film and then analyzed at a later time. Neither fieldnotes nor artifacts offer such detail or flexibility.

There were other ways in which videorecording contributed to my study beyond that which was possible with more traditional ethnographic 
data gathering techniques. MacDougall (1975, p. 121) observes that "[o]ften it is only by introducing new stimuli that the investigator can peel back the layers of a culture and reveal its fundamental assumptions." An informant's response to the videocamera will reveal something about the culture, and the individuals within it. As Hammersley and Atkinson (1983, p. 15) say in response to possible protests that any observer may be intrusive: "How people respond to the presence of the researcher may be as informative as how they react to other situations."

At Cerebellum, I used a full sized recording unit. I "shot from the hip," rather than hold the camera on my shoulder, in a manner which Cerebellum writers seemed to find more friendly or perhaps human than seeing me with a camera always covering one eye. ("Thank goodness," one informant said, referring to this practice, "otherwise you'd look like the Borg!" - a reference to a race of half machine, half human entities appearing in Star Trek: The Next Generation). This alternate placement of the camera also meant that I could focus on the whole scene rather than the smaller frame visible through the viewfinder. This wider perspective allowed me to observe off camera behaviour, and seek out other events to record. I was also more available for interaction with my informants, since I was not barricaded behind my camera (techniques used and recommended for these reasons by $\mathrm{R}$. Goldman-Segall, personal communication, January, 1992). As the days went by, many of the office staff, including employees not involved in the proposal effort, began inquiring about my progress as a "film maker." This interest, even excitement, gave me further openings to discuss what I was doing (for example, not making a film) and to build a relationship with more employees in the office.

Videorecording fixes the transitory nature of events in such a way that analysis becomes more rigorous as the ethnographer has the opportunity to view the data repeatedly and engage in what Goldman-Segall calls "systematic evaluation" (1989, p. 1). I examined the film of the proposal writing again and again, logging events, transcribing conversations, and looking for patterns of interaction.

Margaret Mead (1975), herself an early champion of video use (it must, however, be noted that she was primarily interested in "accuracy" of cultural representation and not in empowering her subjects), called for "the articulate, imaginative inclusion in the whole process of the people who are being filmed" (p. 8). One answer to this issue (for my rather different purposes as 
well as for hers) is to include informants as commentators. My analysis was aided by insights gained from the writers as they viewed themselves at work. Such inclusion of collaborators also built relationships. I recorded these comments in fieldnote form between events during the proposal writing process. Underlying my understanding, of course, lay insights gained from almost two years of visits and more informal observations. For all these reasons, then, the second change $I$ instituted in my approach to ethnography was a shift in primary gathering method from fieldnotes to videotaping.

\section{From Narrative to Model}

The third change I made was to augment my ethnographic narrative with a model of the collaborative writing process. As I began to follow the writing at Cerebellum more closely, I discovered that there were limits to my behaviour as a researcher who was not really an employee at all. I could use all the data I collected to learn generally about the culture of writers at Cerebellum, Inc. but because of the sensitive nature of the proposal writing process I had to be careful how I supported my conclusions to a wide audience. Obviously, the representation of what I found at Cerebellum was crucial to an understanding of another culture for my academic research culture, a role filled traditionally in ethnography by the narrative. For various reasons, however, I decided to add to my narrative of proposal writing at Cerebellum with a model.

Narrative is one powerful way to communicate discoveries. It has several advantages, for example ensuring that "the language of the results and implications [are] in a form that is understandable to and debatable by, various actors in a particular setting" (Howe and Eisenhart, 1990, pp. 7-8). However, controversy over representational forms abounds within the ethnographic community. Most researchers acknowledge that language is not merely a conduit for information. An ethnographic narrative (as a product of research) is a discourse, shaped by the rules of the community which writes such documents: ethnographic researchers. As Herndl (1991) reminds us, readers "judge ethnography by the way it makes the strange or alien seem familiar and palpably real. The imaginative power which wins readers' assent is a matter not simply of knowledge but also of rhetorical skill" (p. 321). It is, therefore, the responsibility of researchers to alert readers to rhetorical approaches and declare that "ethnography is not mainly an empirical methodology capable of discovering and interpreting the 
knowledge of a community; it is more a rhetoric wherein we can begin to discover as much about ourselves as we can about the natives we intend to study" (Kleine, 1990, p. 118).

We do not wish to abandon "telling stories about experience" (Brodkey, 1987, p. 48). What, then, must be declared about these narrative manoeuvres to make them more honest and how might they be supported by other representational forms? Ethnographic accounts have their own rhetorical devices; for example, the "thick description" (Geertz, 1973), which, according to some scholars, "functions as a textual strategy authorizing attempts at ethnographic realism" (Herndl, 1991, p. 321). The question of representation is, again, a difficult one. Wolf (1992) calls this the post-modern problem with ethnography: "Is it possible to represent another culture?" (p. 5). Hammersley (1992) suggests the adoption of "subtle realism" in which it is acknowledged (I am tempted to say confessed) that any illustration is a culturally influenced product and we have therefore abandoned the "ideal of reproduction in favour of selective representation...one of many possible valid accounts" (p. 54). I came to believe that the constitution of a culture must be examined, admitted, and, most important, further methods found for representing data in ways no less rhetorical but perhaps more useful in some contexts, and for some purposes. As Kleine (1990, p. 122) said of the best ethnographic text, our concern should be not that it is true but effective.

Spilka (1992) reminds us that "research in professional writing needs to respond more strongly to needs in pedagogy, while continuing, as well, to respond strongly to needs in theory" (p. 215). I sought also, then, an effective way besides narrative (no matter how subtly realistic) to represent my findings to Cerebellum's business writers and to those "others" such as writing educators who might help them to build their own meanings in written text. Ethnography traditionally calls for a thickening of description, a Burkean complexifying of data to elucidate what might be happening. The standards of Cerebellum's writers, however, were in communicating sensitively to an external audience by simplifying through the use of concise language and graphic representation of ideas.

To serve both audiences — informants and researchers - I wrote first an ethnographic narrative illustrated with excerpts of collaborative events. But I also developed a model or graphic representation as a way to show the collaborative patterns among members of the proposal team as the writing project proceeded. My model represents collaborative writing patterns as levels of engagement with the evolving business proposal text. Three levels 
are postulated with different collaborative activities and players associated with each one. This visual representation offers a concise overview of my findings to share with researchers, educators and informants as a beginning point for further discussion of collaborative writing practices.

As Pemberton (1993) notes: “[I]n order to teach writing effectively, we must know as much as possible about how people write; in order to know how people write, we must observe them writing under a variety of conditions and describe what we observe them doing" (p. 41, emphasis mine). My descriptions construct and represent the world of Cerebellum writers as I saw it: in both narrative and visual form.

Caught between the Scylla of intricacy and the Charybdis of reductionism, I sought a fair, effective and defensible path. Within the narrative I sought to capture the complexities and the drama of the proposal writing collaboration. The model I postulate is intentionally a reduction and abstraction that, nevertheless, renders extremely intricate acts into a more manageable and useful shape. Pedagogical interests dictate that we show research results in a form accessible both to educators who seek to intervene in the writing process and to writers engaged in the composition. Finally, I wanted to present a model of collaboration to focus further research into the social writing process.

\section{Conclusion}

Perhaps in the final analysis, I agree with Van Maanen (1988) that "the value of ethnography...is found not in its analysis and interpretation of culture, but in its decision to examine culture in the first place" (p. 149). My decision to examine the literacy behaviours of proposal writers at Cerebellum Inc. involved me in "pushing the envelope" of ethnography. I first reconsidered interpretation adding more emphasis on the building of relationships with informants. Second, I rethought the use of fieldnotes and added videorecording to improve data gathering. Finally, I recognized some limitations to the ethnographic narrative and added a model to represent my findings. Through all of these changes, I never completely abandoned former approaches to ethnography but rather expanded its traditional repertoire for my research situation. I argue, therefore, that my approach expands the bounds of ethnography in this particular situation with good reason, and is appropriate and valuable for the intercultural sharing of insights into collaborative business writing. 


\section{References}

Agar, M. H. (1980). The professional stranger: An informal introduction to ethnography. New York: Academic Press.

Anderson, G. L. (1989). Critical ethnography in education: origins, current status and new directions. Review of Educational Research, 59(1), 249_ 270.

Best, J. W. (1981). Research in education (4th edition). Englewood Cliffs, NJ: Prentice-Hall.

Brodkey, L. (1987). Writing ethnographic narratives. Written Communication, $4(1), 25-50$.

Brown, R. L. \& Herndl, C. G. (1986). An ethnographic study of corporate writing: job status as reflected in written text. In B. Couture (Ed.), Functional approaches to writing: Research perspectives (pp. 11-25). London: Frances Pinter.

Doheny-Farina, S. (1993). Research as rhetoric: Confronting the methodological and ethical problems of research on writing in nonacademic settings. In R. Spilka (Ed.), Writing in the workplace: New research perspectives (pp. 253-267). Carbondale and Edwardsville: Southern Illinois University Press.

Etter-Lewis, G. (1991). Blackwomen's life stories. In G. Etter-Lewis, Women's words (pp. 43-58). London and New York: Routledge.

Ede, L. \& Lunsford, A. (1990). Singular texts/plural authors: Perspectives on collaborative writing. Carbondale and Edwardsville: Southern Illinois University Press.

Geertz, C. (1973). Thick description: Toward an interpretive theory of culture. In C. Geertz, Interpretation of cultures (pp. 3-30). New York: Basic Books.

Goetz, J. P. \& LeCompte, M. D. (1984). Ethnography and qualitative design in educational research. Orlando, Florida: Academic Press.

Goldman-Segall, R. (1989). Thick descriptions: A language for articulating ethnographic media technology. Unpublished manuscript.

Massachusetts Institute of Technology, Boston. 
Hammersley, M. (1992). What's wrong with ethnography? New York: Routledge.

Hammersley, M. \& Atkinson, P. (1983). What is ethnography? In H. Hammersley \& P. Atkinson, Ethnography: Principles in practice (pp. 3-30). London and New York: Routledge.

Howe, K. \& Eisenhart, M. (1990). Standards for qualitative (and quantitative) research: A prolegomenon. Educational Researcher, 19(4), 2-9.

Jacob, E. (1987). Qualitative research traditions: A review. Review of Educational Research, 57(1), 1-50.

Kleine, M. (1990). Beyond triangulation: Ethnography, writing and rhetoric. Journal of Advanced Composition, 10(1), 117-125.

Lather, P. (1991). Getting smart: Feminist research and pedagogy with/in the postmodern. New York: Routledge.

MacDougall, D. (1975). Beyond observational cinema. In D. MacDougall (Ed.), Principles of visual anthropology (pp. 109-124). Hawthorne, NY: Aldine de Gruyter.

Mead, M. (1975). Visual anthropology in a discipline of words. In D. McDougall (Ed.), Principles of visual anthropology (pp. 3-10). Hawthorne, NY: Aldine de Gruyter.

Moss, B. J. (1992). Ethnography and composition: Studying language at home. In G. Kirsch \& P. A. Sullivan (Eds.), Methods and methodology in composition research (pp. 153-171). Carbondale and Edwardsville: Southern Illinois University Press.

Pemberton, M. A. (1993). Modeling theory and composing process models. College Composition and Communication, 44(1), 40-58.

Spilka, R. (1993). Influencing workplace practice: A challenge for professional writing specialists in academia. In R. Spilka (Ed.), Writing in the workplace: New research perspectives (pp. 124-140). Carbondale and Edwardsville: Southern Illinois University Press.

Van Maanen, J. (1988). Tales of the field: On writing ethnography. Chicago: University of Chicago Press.

Wolf, M. (1992). A thrice told tale: feminism, post-modernism and ethnographic responsibility. Stanford: Stanford University Press. 